\title{
De como D. Quixote enfrentou os monstruosos moinhos: a mediação teatral e a escola na perspectiva da ação cultural
}

\author{
Heloise Baurich Vidor ${ }^{1}$
}

\section{Resumo}

Este artigo tem como eixo de discussão o conceito de mediação relacionado ao campo da ação cultural, na modalidade específica que é a ação artística, em especial o teatro. Pretende-se revisar esta noção focando o papel do mediador teatral, que no contexto brasileiro acumula as competências de professor e artista, de modo a analisar as dificuldades e as potencialidades que este profissional encontra na realização de projetos artísticos propostos na instituição escolar.

Palavras-chave: mediador; teatro; pedagogia; ação cultural; professor-artista.

\section{Abstract}

This paper's discussion axis lays on the concept of mediation related to the field of cultural action, in the specific modality of the artistic action, particularly the theatre. It is intended to review this concept, focusing on the role of the theatre mediator. In the Brazilian context, this role entail both skills of teacher and artist; in this way, it seeks to analyze the difficulties and potentialities that such professional encounters in the production of artistic projects proposed in the school.

Keywords: mediator; Theatre; pedagogy; cultural action; teacher-artist

A aventura vai guiando as nossas coisas melhor do que pudéramos desejar. Vê lá, amigo Sancho Pança, aqueles trinta e poucos mais desaforados dos gigantes com os quais penso travar batalha e tirar de todos a vida.

Miguel de Cervantes

\section{Introdução}

A aproximação ao tema da ação cultural, fruto do acompanhamento da disciplina Ação Cultural em Cena: Contextos e Processos² remeteu-nos a uma retrospectiva de nossa história com o teatro, que está pautada, em vários momentos, pelo conceito acima referido e sua inserção no espaço da escola. O início de nossas atividades teatrais no período da adolescência, num grupo de teatro nascido na Escola Técnica Federal de São Paulo, em projeto extracurricular, seguido pela precoce atuação como

\footnotetext{
${ }^{1}$ A autora é Bolsista da FAPESC/SC - Brasil.

2 Esta disciplina foi oferecida pelo Programa de Pós-Graduação em Artes Cênicas da Eca /USP, no segundo semestre de 2011, e foi ministrada pela Profa. Dra. Maria Lúcia de Souza Barros Pupo.
} 
professora de teatro, também no âmbito extracurricular, no Colégio de São Bento $\mathrm{SP}$, por sete anos, já nos colocava em contato com as questões que se relacionam à formação teatral e ao ensino do teatro na escola.

Com uma formação universitária focada na pedagogia do ator - Bacharelado em Interpretação Teatral - e pós-graduação na área de Educação e Cultura e Pedagogia do Teatro, nosso perfil profissional acumula a dupla competência de professora e atriz. Esta dupla competência nos levou à atuação como professora universitária ${ }^{3}$, na área de Práticas Teatrais e, posteriormente, na área de Pedagogia do Teatro - formação de professores de teatro - lugar que atualmente ocupamos.

Devido a esta trajetória, nos pareceu coerente e instigante focar a presente discussão no potencial da ação cultural no espaço da escola, tendo na figura do mediador ${ }^{4}$ personagem central capaz de articular as ações e enfrentar as adversidades recorrentes do encontro - nem sempre harmônico - entre arte e educação. Para isso, propomos ao longo do texto revisar conceitos relacionados aos temas mencionados e problematizarmos questões que perpassam nossa prática como mediadora teatral e formadora de mediadores teatrais.

\section{Mediar sem embrutecer: elos encadeadores de uma complexa ação cultural, artística, teatral}

A palavra mediação, em linhas gerais, designa a função de relacionar dois termos ou dois objetos em âmbitos variados. Outra forma de definir tal termo, entretanto, é especialmente rica quando relacionamos esta noção ao conceito de ação cultural:

\footnotetext{
"Entre o estímulo inicial (objeto, propriedades do objeto) e a resposta verbal que se encontra no fim de uma cadeia de ações, há elos intermediários que são, ao mesmo tempo, as respostas aos estímulos que os precedem e, por sua vez, estímulos para os elos que seguem." (DUBOIS; GUESPIN; MARCELLESI; MARCELLESI; MEVEL, 2006: 405).
}

A imagem de elos intermediários que se afetam pelos que seguem e são afetados pelos que precedem numa ação complexa, encadeada, apresenta-se como uma imagem potente que traduz a função de mediar dentro da perspectiva de um processo artístico inserido no âmbito de uma ação cultural. A ação cultural, em oposição à fabricação cultural, é um processo que não tem um fim determinado previamente, nem

\footnotetext{
${ }^{3}$ Compomos o quadro de professores efetivos do Departamento de Artes Cênicas da UDESC/ Florianópolis -SC.

${ }^{4}$ Ao longo do texto alguns termos foram colocados em itálico para ressaltá-los como conceitos chaves na discussão.
} 
etapas previamente estabelecidas, ou seja, é uma aposta a partir de certas balizas, de modo que o processo importa mais que os fins (COELHO, 2004), numa ação que é complexa e encadeada como os elos de uma grande e grossa corrente.

O termo ação cultural, em linhas gerais, abriga um projeto humanista, no qual forças idealistas de liberdade agem na contramão do pensamento liberal dominante (CARASSO, 2009). Sinteticamente, o termo é colocado dentro da perspectiva de aproximação entre o público e as obras culturais e artísticas, em termos de fruição e criação.

A delimitação dos conceitos de arte e cultura-arte como sendo o contrário da cultura (COELHO, 2008); ou o fenômeno da arte como ponto de partida para a discussão sobre a cultura (ARENDT, 2009); ou a arte como sendo a crítica da cultura, sua reflexão aguda e não um produto cultural (TENDLAU, 2010 a partir da leitura de W. Benjamin) - abre perspectivas para a diferenciação entre ação cultural e ação artística (CARASSO, 2009). A partir daí, propomos o seguinte raciocínio: refletirmos sobre a noção de mediação no âmbito da ação cultural, na modalidade específica que é a ação artística, em especial o teatro.

No texto Mediação Artística, uma tessitura em processo (PUPO, 2011), a autora reflete sobre a noção de mediação artística através da análise de uma estrutura de mediação ${ }^{5}$. Duas questões, por ela abordadas, merecem destaque para a presente discussão: a mediação como modalidade de criação - "formulações e experimentações das crianças e jovens e a reflexão sobre a arte e sua inserção cultural" (PUPO, 2011: 121); e a figura do pedagogo-artista como verdadeiro mediador teatral: "essa é, inclusive, uma vertente que caracteriza a formação docente em nosso país, (...) uma dupla competência, artística e pedagógica, reunida em um único profissional (...)" (PUPO, 2011:114).

Não pretendemos focar nossa análise numa estrutura de mediação cultural aos moldes franceses, onde temos um triângulo composto por: professor da escola, mediador da instituição e artista. $\mathrm{O}$ destaque dado às questões acima mencionadas nos remete ao mediador artístico, que é o propositor/agente da ação e acumula as competências de professor e artista, de modo que o que se espera deste profissional é que ele faça as pontes entre a instituição em que atua e as artes da cena.

Tendo em vista que nossa atuação profissional se dá na cidade de Florianópolis, capital do Estado de Santa Catarina, região sul do Brasil, a opção de focar a discussão no mediador justifica-se por dois motivos. Em primeiro lugar porque verificamos que o

${ }^{5}$ A instituição mencionada é a Maison du Geste et de l'Image, situada em Paris e mantida pela Prefeitura da cidade. 
Estado de Santa Catarina não possui um projeto de política pública consistente para a cultura e para a arte. Diante de uma situação de precariedade, que se reitera pela "cultura de clientelismo" que acomete, em alguns casos, as próprias pessoas interessadas da área de cultura e das artes - abrindo brechas para que o favoritismo ocorra - o que predomina, neste contexto, é uma visão extremamente acentuada de cultura como produto a ser gerado e consumido e não como ato, fazer processual. Diante deste quadro, propomos focar a análise na pessoa do mediador, por acreditarmos que o que faz a diferença, tanto no acontecimento ou não da ação, quanto na sua qualidade, está mais relacionado à "qualidade quixotesca", ou seja, idealista da pessoa que a propõe e/ou realiza, do que na dependência de uma estrutura de mediação, que implica em investimento relacionado às políticas públicas.

Estas impressões são fruto da nossa atuação no contexto catarinense, entretanto se relacionam com uma esfera muito mais abrangente, pois, segundo Hannah Arendt (2009), por estarmos inseridos numa sociedade de massas, que se apodera dos objetos culturais criando uma cultura de massas ocupada com o entretenimento e o consumo - o que se configura como uma verdadeira ameaça aos objetos culturais podemos concluir que, em maior ou menor grau, estamos todos, independentemente do contexto, afetados por estas questões que assumem um caráter global.

Em segundo lugar, a opção de focar a discussão no mediador é porque temos na capital do Estado de Santa Catarina uma Licenciatura em Teatro, criada em 1986, que tem uma relação direta com a produção artística da cidade, bem como com as ações de aproximação de crianças, jovens e adultos com as artes da cena.

Contudo, apesar de termos os mediadores, como não temos a estrutura de mediação, o que se vê são ações pontuais em diversos contextos, desvinculadas de um projeto de ação cultural. Apesar de terem, na maioria dos casos, ótimas intenções por parte dos proponentes, essas ações não têm o impacto necessário diante da sociedade, que possa mobilizar uma reivindicação pela criação de um programa para a cultura por parte do governo.

Observa-se, como consequência destas propostas pontuais, a falta de recursos, de planejamento, de estrutura que leva à falta de continuidade e comprometimento, acabando por se caracterizar como "trabalho voluntário" e aí, abrir brechas para que um caráter assistencialista da prática teatral se instale. Apesar de muitos dos mediadores teatrais terem passado pela Licenciatura, observa-se, também, falta de clareza 
e interesse sobre o potencial da ação teatral numa perspectiva de ação cultural, de modo a ir além de uma oficina pontual: uma ação que estabeleça um espaço de criação, reflexão e fruição estética. Este é um aspecto grave, pois se a função primeira da mediação é aproximar o público da obra, ou a pessoa da linguagem artística, se esse trabalho for bruto e descontínuo pode surtir o efeito contrário.

O termo bruto foi escolhido inicialmente por ser contrário ao termo delicado. Ou seja, o teatro experimentado com pessoas que não se inserem no contexto do teatro profissional, se não for delicado em suas proposições e expectativas, pode trazer efeitos desastrosos, pode afastar as pessoas desta linguagem - não só do fazer, mas também do apreciar ${ }^{6}$. Neste sentido, por exemplo, na escola, apesar de ser, a princípio, um ganho para a área a obrigatoriedade do teatro nesta instituição ${ }^{7}$, dependendo de como for conduzida a inserção, os resultados podem ser contraproducentes. Esta é uma questão extremamente complexa, um verdadeiro desafio a ser enfrentado e que tem sido foco de discussão na área.

Voltando ao termo bruto pensamos que a imersão que realizamos na obra de Jaques Rancière , especialmente a partir da leitura dos textos $O$ Espectador Emancipado e $O$ Mestre Ignorante, ampliou sobremaneira o seu sentido. Rancière defende a educação emancipadora contrariamente a uma educação que leve ao embrutecimento. Justamente quando estamos diante de uma proposição pautada na valorização dos sentidos, como é o teatro, a delicadeza é fator essencial. Quando usamos o termo delicadeza, não estamos nos remetendo ao aspecto de "suavidade" nas ações, mas à real consciência do potencial do teatro para promover a autonomia, a partir da perspectiva de “igualdade de inteligências", base da argumentação de Rancière. A explicação, colocada pelo autor como elemento embrutecedor na relação de aprendizado, dá lugar à ação de decifrar os sentidos de algo que ambos (professor e aluno) desconhecem, mediante uma situação criada pelo professor, na qual ele também é convidado a participar. É fundamental que algo seja colocado entre professor e aluno, para que a operação de desvendamento, tradução dos sentidos, se revele. Num processo de criação artística aos moldes de uma ação cultural, o mediador cria a situação, a partir de certos recursos

\footnotetext{
${ }^{6}$ Menção à proposta triangular para o ensino da arte, na qual o conhecimento em artes se dá por três ações: fazer, apreciar e contextualizar (BARBOSA, 2006)

7 Após a publicação da LDB 9394/96, na qual a arte foi reconhecida como área de conhecimento no currículo escolar, possibilitando a inserção das diferentes linguagens artísticas (música, artes visuais, teatro, dança) a serem trabalhadas na disciplina Artes.
} 
e objetivos, mas aceita correr o risco de não ter um fim determinado. Aceita que o desenrolar do processo se dê entre ele e os participantes - mediados pela obra/projeto - que irão, ao longo do tempo, decifrar os sentidos e construir conhecimento - o caminho é construído por todos enquanto é trilhado.

A princípio, o teatro pode ser um lugar especialmente fértil para o que propõe Rancière. Mas, concretamente, que tipo de proposições pode fazer um professor de teatro, comprometido com as questões que coloca o autor francês, na sua prática, seja em escolas, seja em outros locais que abrigam esta linguagem artística, para que as ações ganhem envergadura? Voltando ao contexto onde atuamos, colocamos a seguinte questão: se em Santa Catarina nós temos os mediadores teatrais mas não temos as estruturas de mediação que dão sustentação ao seu trabalho, como e onde propor ações culturais em teatro que rapidamente não se esmoreçam?

\section{A escola como campo fértil para a ação teatral na perspectiva da ação cultural}

A pergunta lançada nos remete ao início de nossa história com o teatro, mencionada na introdução deste texto e que agora terá alguns aspectos detalhados. Com catorze anos, começamos a fazer teatro em um grupo que nasceu na Escola Técnica

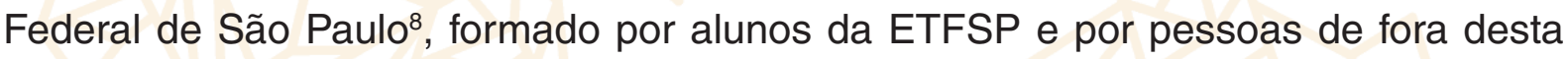
instituição - nós, por exemplo. O professor ${ }^{9}$ (ou mediador ou ainda professor-mediador, ou melhor, tutor) de teatro - não sabemos dizer qual desses nomes o define melhor teve, podemos afirmar com segurança, uma atuação determinante, tanto para o nascimento do grupo IVAMBA, quanto para sua existência por aproximadamente dez anos, que de amador tentou se transformar em profissional e que, neste momento, acabou ${ }^{10}$.

Ter alguém como aquele professor, que fazia a ponte com a instituição, assistia alguns ensaios, sugerindo espetáculos para serem assistidos, filmes e livros para serem fruídos, que trazia artistas e intelectuais para darem palestras e oficinas para o grupo, nos fez pensar que estávamos no âmbito de uma ação cultural em teatro, com um mediador atuando de forma significativa - ainda que não usássemos esses termos. Portanto, iniciamos - e podemos dizer que tivemos parte de nossa formação

\footnotetext{
${ }^{8}$ Usaremos a partir deste momento a sigla ETFSP.

${ }^{9} \mathrm{Na}$ época o professor era Reynuncio Napoleão de Lima.

10 Dos mais de trinta componentes que transitaram pelo IVAMBA, durante sua longa existência, foram poucos os que se profissionalizaram. Os outros tomaram outros rumos profissionais, mas os laços afetivos até hoje são preservados, marcados por encontros anuais de confraternização.
} 
teatral - num grupo amador/âmbito de ação cultural, dentro da instituição escolar, do qual participamos por oito anos.

Este relato traz aspectos interessantes para refletirmos sobre o questionamento anteriormente lançado. O primeiro deles é o fato da ação artística (teatral) ter acontecido dentro da instituição escolar - uma escola de cursos técnicos nas áreas das exatas, prioritariamente; depois a constatação de que a ação do professor não era uma ação de mediação, mas várias ações de mediação - ele mediava vários aspectos que compreendiam a ação como um todo: as questões burocráticas com a Instituição, a relação dos alunos com as obras teatrais e/ou cinematográficas em cartaz na cidade, a relação entre os artistas da cidade e aquele grupo de jovens, a relação entre a obra o espetáculo que estava sendo criado - e o momento social/político em que vivíamos através de provocações para refletirmos durante o processo, a divulgação de festivais e encontros que pudéssemos nos apresentar. Ele não era um membro do grupo efetivamente, mas era alguém que "alimentava nosso desejo de fazer e ver teatro", parafraseando Pupo (2009), sem nos dizer como deveríamos fazer, sem pautar sua relação conosco através de explicações, consideradas embrutecedoras por Rancière.

Outro aspecto a se pensar é a questão do amador versus profissional. Este momento transitório gerou uma crise que encerrou as atividades do grupo, pois fez com que nos deparássemos com fatores determinantes para a continuidade do trabalho: época de escolha profissional dos jovens; impossibilidade de continuar no espaço da instituição já que os fundadores do grupo não eram mais alunos da ETFSP; ambição por aprimoramento técnico, portanto, mais dedicação ao grupo, investimento em cursos profissionalizantes. Neste sentido, concordamos com Koudela (2011), quando diz que se a ação teatral for considerada como local de criação, reflexão e inserção cultural, ela pode transcender esta ideia de oposição entre amador e profissional, mas vale lembrar que "a designação de teatro amador guarda embutido o termo amor" (KOUDELA, 2011:17) e isso nos remete, novamente, à dimensão "quixotesca" que envolve tanto o mediador teatral, quanto os participantes da ação, pois do contrário a ação pode virar mera necessidade de contrapartida, e com este fim claramente determinado, aproximar-se do que Coelho (2004) define como fabricação cultural.

Um terceiro aspecto importante é a questão do tempo, aliado necessário para que uma ação ganhe envergadura. No âmbito de uma ação cultural, que pressupõe um processo sem um fim determinado, que tenha a oportunidade e o privilégio de "perder- 
-se no caminho", sem a cobrança interna - dos próprios participantes - e externa - da instituição que acolhe a ação - e que o caminho seja realmente construído enquanto é trilhado, é imprescindível que se tenha tempo, que "se permita o tempo".

Voltando à nossa prática atual e ao enfoque da presente discussão na perspectiva de uma ação artística em teatro que coloca em interface o papel do mediador teatral e o contexto escolar como campo fértil para que processos teatrais aconteçam, podemos observar que, apesar de termos os mediadores teatrais - professores de teatro licenciados - as ações teatrais nas escolas ainda não acontecem plenamente. Mas, ainda assim, acreditamos que o perfil duplo deste profissional que, a princípio, dispensaria uma estrutura de mediação (aos moldes franceses) para efetivar as parcerias entre docentes e artistas, é figura-chave neste processo, pois ele tem as condições para diluir preconceitos arraigados dos artistas em relação aos educadores e vice-versa, facilitando o convívio entre os pressupostos da arte (como radicalidade, instabilidade, olhar crítico dos processos culturais) e as questões da instituição escolar, sem desconsiderar, entretanto, que este é um terreno que inevitavelmente será marcado por tensões.

Outra questão que nos parece importantíssima na ação deste profissional diz respeito à possibilidade de pensarmos a noção de mediação teatral como uma rede de ações que exigirá uma dinamização da sua atuação para enfrentar as adversidades do local onde atua (escola ou qualquer outro). Os professores e futuros professores de teatro se quiserem estabelecer processos que estejam no âmbito da ação cultural, colocando-se como mediadores culturais, ou, aqui no caso, teatrais, precisam estar conscientes de que suas ações são mais abrangentes do que a função de "dar aulas", buscando verificar quais são as ações em rede que o mediador teatral pode realizar neste contexto.

Um último aspecto - e talvez o mais desafiador - que o mediador teatral precisa enfrentar é fazer com que a escola (e outras esferas que também abrem suas portas para o teatro) acolha a ação artística, tendo em vista a "pedagogia da razão interior" de que fala Coelho (2004) ou a "ampliação da esfera de presença do ser", segundo Montesquieu (2008), e não como "tábua de salvação" que traz consigo suposições de que teatro ensina a ser cidadão, ensina a ter um objetivo na vida, ensina a não ser violento (Icle, 2010), entre outras. Estas expectativas colocadas a priori minam a premissa de que numa ação cultural os fins não podem estar determinados, ou seja, 
atribuem funcionalidade à arte, para justificar e acolher sua presença nestes meios. O teatro tem potencial para "ampliar a esfera do ser" e isto é muito mais abrangente e contundente do que justificá-lo sob esta ou aquela função específica.

\section{Considerações Finais}

Encerramos esta reflexão com a certeza de que a associação entre cultura e educação abre um campo fértil para o desenvolvimento de ações artísticas dentro da perspectiva da ação cultural, privilegiando uma perspectiva humanista que prevê um idealismo de quem a propõe e a realiza. Neste sentido, a escola pode ser olhada como uma instituição cultural, um espaço potente para abrigar estas ações, ainda que se apresente como espaço de tensão e confronto com as particularidades da arte.

Nossos apontamentos não pretendem ditar modos de agir de um mediador teatral "ideal", mas trazer à tona questões que possam problematizar nossa própria atuação, que tem como responsabilidade a ação mediadora e a formação de mediadores, e promover, cada vez mais, a inserção deste profissional em uma sociedade marcada pelo consumismo e pelo embrutecimento. O projeto idealista que marca uma ação cultural é o aspecto que enobrece o papel do mediador (cultural, artístico, teatral) que, com delicadeza e perspicácia, pode derrotar os "monstruosos moinhos de vento", como o fez, bravamente, o herói de Miguel de Cervantes.

\section{Referências Bibliográficas}

ARENDT, Hannah. Entre o passado e o futuro. Tradução: Mauro W. Barbosa. São Paulo. Perspectiva, 2009.

BARBOSA, Ana Mae. Arte-Educação no Brasil. São Paulo. Perspectiva, 2006.

BRASIL. Parâmetros Curriculares Nacionais - Artes - Ensino Médio. Linguagens, códigos e suas tecnologias. Brasília: MEC, 1999.

COELHO, José Teixeira. Dicionário crítico de política cultural. São Paulo: Iluminuras, 2004. O que é ação cultural. São Paulo: Brasiliense, 1988.

A cultura e seu contrário. São Paulo: Iluminuras, 2008.

CUNHA, Newton. Dicionário SESC - a linguagem da cultura. São Paulo. Perspectiva: SESC São Paulo, 2003.

CARASSO, Jean-Gabriel. “L'action culturelle est un humanisme”. Tradução: Maria Lúcia de Souza Barros Pupo. In GUITART, Cécil, La bataille de l'imaginaire. Toulouse: Editions de l'Attribut. Les rencontres d'Archimèdes, 2009, p. 249-251.

DUBOIS, Jean; MATHÉE, Giacomo; GUESPIN, Louis; MARCELLESI, Christiane; MARCELLESI, Jean-Baptiste; MEVEL, Jean-Pierre. Dicionário de Lingüística / [direção e coordenação geral da tradução Izidoro Blinkstein]. São Paulo. Cultrix, 2006. 
FERREIRA, Aurélio Buarque de Holanda. Dicionário Aurélio da língua portuguesa. Curitiba, Positivo, 2010.

GARCIA, Nestor. Canclini. Leitores, espectadores e internautas. Tradução Ana Goldberger. São Paulo: Iluminuras, 2008.

ICLE, Gilberto. Pedagogia Teatral como cuidado de si. São Paulo. Hucitec, 2010.

KOUDELA, Ingrid. O que é teatro amador? In a Parte XXI - Revista do Tusp. São Paulo. USO, 2011, p.15-24.

MONTESQUIEU, O gosto In COELHO, Teixeira. A Cultura e seu Contrário. São Paulo: lluminuras, 2008.

PAVIS, Patrice. Dicionário de Teatro. São Paulo. Perspectiva, 2001.

PUPO, Maria Lúcia de Souza Barros. Para alimentar o desejo de teatro. In Revista Sala Preta no. 09. São Paulo. ECA/USP, 2009 p. 269-278.

Mediação Artística, uma tessitura em processo. Florianópolis: Revista Urdimento No. 17 PPGT/UDESC, 2011 p. 113-121.

RANCIÈRE, Jacques. A partilha do sensivel - Estética e Política. Tradução: Mônica Costa Netto. São Paulo. Ed. 34, 2005.

O mestre ignorante - Cinco lições sobre emancipação intelectual. Tradução: Lilian do Valle. Belo Horizonte. Autêntica, 2010.

O espectador emancipado. Tradução: Daniele Ávila. In Revista Urdimento vol 1, no. 15. Florianópolis. Ceart/UDESC, 2010 p.107-122.

SAAVEDRA, Miguel de Cervantes. O engenhoso fidalgo D. Quixote de La Mancha. Tradução: Sérgio Molina. São Paulo. Ed 34, 2002.

TENDLAU, Maria. Teatro vocacional e a apropriação da atitude épica/dialética. São Paulo. Hucitec, 2010. 